\title{
SÃO MATEUS: CONTEXTOS DA EJA E PERSPECTIVAS DO PROEJA A PARTIR DAS DETERMINAÇÕES DO IMAGINÁRIO SOCIAL
}

\author{
Márcia Alessandra de Souza Fernandes ${ }^{1}$, MARia José de ReSEnde FerReira ${ }^{2}$ \\ Pós-graduação Lato Sensu em PROEJA, Instituto Federal do Espírito Santo \\ E-mail: marciaasf@bol.com.br, majoresende@yahoo.com.br
}

\begin{abstract}
RESUMO
Este estudo parte das reflexões sobre Educação de Jovens e Adultos realizadas no curso de Especialização do Programa Nacional de Integração da Educação Profissional com a Educação Básica na modalidade de EJA (PROEJA). O processo de implantação do PROEJA nas escolas municipais, reforça a necessidade de conhecer a EJA local, (re)conhecendo desafios e possibilidades. Resgatamos o conceito de imaginário social de Castoriadis (1995) que afirma que a sociedade resulta das representações ligadas à multiplicidade de outras representações. Buscamos identificar e refletir sobre o imaginário que alunos e professores das turmas iniciantes e concludentes da EJA da EMEF Professor João Pinto Bandeira possuem sobre ela. Empreendemos pesquisa qualitativa de caráter descritivo com a realização de estudo de caso. Realizamos entrevistas estruturadas. A análise dos dados confirma, entre outras questões, a discussão de Paiva (2006) e Arroyo (2003) quando defendem o direito à educação de qualidade e não apenas acesso à escola, apontando a necessidade de vincular maior discussão/integração entre educação e trabalho.
\end{abstract}

Palavras-chaves: imaginário social, direito à educação, PROEJA, EJA.

\section{A EJA E A CHEGADA do PROEJA EM São MATEUS}

O processo de implantação do Programa de Integração da Educação Profissional à Educação Básica na Modalidade Educação de Jovens e Adultos (PROEJA) em São Mateus vem dando destaque a assuntos que, embora há muito urgentes, não conseguiam espaço na pauta da educação local. O presente trabalho é, em si, fruto desse processo, uma vez que ele resulta das reflexões sobre a Educação de Jovens e Adultos (EJA) realizadas durante o curso de Especialização em Educação Profissional Técnica Integrada à Educação Básica na Modalidade de EJA e, realçadas quando o Instituto Federal do Espírito Santo (Ifes) campus São Mateus propôs à Secretaria Municipal de Educação (SME) parceria para a implantação do Programa no Ensino Fundamental, no caso, Formação Inicial e Continuada - PROEJA/FIC . Imaginamos que nesse processo de implantação, algumas questões devem permear as discussões no sentido de se conhecer um pouco mais este novo campo de atuação do Ifes, com sujeitos e trajetórias escolares bem diferentes dos que, historicamente, vêm constituindo a EJA. Assim, a chegada do PROEJA reforça a necessidade de se conhecer a EJA local, de maneira a (re)conhecer seus desafios e suas possibilidades. Nesse sentido, perguntamos: Qual é o imaginário social instituído da EJA?

Buscando respostas, ainda que provisórias, partimos dos conceitos-chave propostos pelo filósofo Cornelius Castoriadis (1995), para quem a sociedade é o produto de uma instituição imaginária que não se esgota em uma perspectiva de explicação fundada na determinação de ordem natural, material e histórica. Para ele, a compreensão da sociedade, enquanto prática humana, "se dá imediatamente como coexistência de uma quantidade de termos ou de entidades de diferentes ordens" (CASTORIADIS, 1995, p. 211), isto é, a sociedade resulta das representações ligadas a uma multiplicidade de outras representações, as quais são capazes de instituí-la no plano imaginário.

Sendo, o imaginário social, entendido como a instância na qual o homem produz sentidos para as suas ações, ele tem se constituído como importante categoria para a compreensão do sentido que o sujeito atribui à instituição escolar, entre outras. Na educação, seus processos podem ser entendidos como produções

\footnotetext{
${ }^{1}$ Licenciatura em Letras Português pela UFES e pós-graduanda do Curso de Pós-Graduação LATO SENSU em Educação Profissional Técnica Integrada à Educação Básica na modalidade de jovens e adultos - PROEJA, Ifes Campus São Mateus.

${ }^{2}$ Mestre em Educação ISPETP/Cuba/UFGO. Coordenadora e Professora do PROEJA, Ifes Campus Vitória. Membro do Grupo de Pesquisa PROEJA/CAPES/SETEC-ES.
} 
imaginárias, uma vez que são constituídos a partir dos modelos de homem e de sociedade que se deseja instituir. Exemplo disso é a escola que, ao longo da história, atuou como refinado instrumento de dominação e de mistificação da razão.

\section{À BuSCA Do INSTITUíDo}

O estudo proposto nos levou a desenvolver uma pesquisa qualitativa de caráter descritivo com a realização de um estudo de caso, buscando compreender um fenômeno social complexo, tendo como objetivo identificar e refletir sobre o imaginário que alunos e professores das turmas iniciantes e concludentes da EJA da Escola Municipal de Ensino Fundamental Professor João Pinto Bandeira possuem sobre essa modalidade. Para tanto, a coleta de dados deu-se por meio de entrevistas estruturadas, aplicadas a 30 alunos, sendo 08 das turmas iniciantes e 22 concludentes. De um universo de 15 professores, 08 foram entrevistados.

Outra ação empreendida foi a análise documental de diversas fontes escritas: documentos da SME e SER (Superintendência Regional de Educação), com informações sobre número de matrícula e nome de escolas de suas redes de ensino; a consulta ao Instituto Brasileiro de Geografia e Estatística (IBGE); documentos da secretaria da própria escola, intitulada Documentos Propostas - EJA - que além de descrever, apresentar e justificar a modalidade na rede municipal de educação, também traz listagem de conteúdos por período, modelo de ficha de acompanhamento individual para as séries iniciantes, modelo de documento como declaração e histórico escolar que a escola deve expedir. A investigação iniciou-se com a realização das entrevistas aos alunos. Todos os alunos das turmas iniciantes e concludentes foram convidados a participar. De acordo com a secretaria da Escola, 100 pessoas se matricularam nas turmas iniciante e concludente, no 20 semestre de 2009; entretanto, frequentando no mês de novembro, eram apenas 68; sendo 13 na série inicial e 55 na série final. Ressaltamos que desses 68, nem todos frequentavam regularmente as aulas, pois alguns trabalhavam em regime de escala e outros, ainda, por questões pessoais, não conseguiam frequentar assiduamente as aulas. Em relação à entrevista dos estudantes, elas versaram sobre assuntos de caráter sociocultural, da trajetória escolar e aqueles relacionados à experiência de aluno da EJA.

No que diz respeito aos professores, optamos por entrevistar aqueles que têm mais tempo no trabalho com a modalidade. Entendemos que esses, considerando as suas vivências, poderiam ajudar a conhecer o que vem se instituindo, ao longo do tempo, em torno do pensar e do fazer na EJA nesta Escola. São, ao todo, 8 professores em efetivo exercício de regência de sala: 2 das séries iniciais e 6 das séries finais. De acordo com a abordagem das entrevistas dos professores, agrupamos as questões a partir dos aspectos socioculturais, aspectos relacionados à experiência docente e aqueles que evidenciam a sua visão com relação à modalidade em si.

\section{OS ALUNOS DA EJA}

Considerando as informações coletadas, podemos afirmar que os dois grupos de alunos possuem características bem diferentes. Quase a totalidade deles têm histórico de reprovação no regular ${ }^{3}$ e apenas um caso de reprovação na EJA. No que diz respeito às experiências estudantis, podemos afirmar que da totalidade de alunos entrevistados, 27 disseram ter frequentado o ensino regular e afirmam haver diferenças entre este e a EJA. O Quadro 01 mostra o que eles indicaram como as principais diferenças.

Os conteúdos são incompletos;

O tempo é insuficiente para o estudo;

Aprende-se menos;

$O$ ensino é acelerado;

Alguns desanimam no meio do processo;

Aprende-se a conviver com pessoas de diferentes

idades;

Pode-se conciliar trabalho e estudo;

A relação professor $X$ aluno é mais tranqüila, madura e proveitosa;

Tem-se mais vontade de estudar;

A EJA é mais rápida.

\footnotetext{
${ }^{3}$ Ao longo do texto, empregaremos a expressão ensino regular em itálico por entendermos a problemática que o termo revela, ao pressupor a existência de um ensino em estado de irregularidade.
} 
Quando indagados sobre como se sentem sendo alunos da EJA, a maioria afirma que se sente bem, feliz, satisfeita, realizada e até vitoriosa; no entanto, um grupo menor diz que não gosta, sente-se envergonhado, menos capaz, e tem consciência do preconceito fora da escola. Nessa questão, percebemos empolgação e satisfação generalizada nas respostas dos alunos iniciantes, cujas trajetórias de vida são marcadas pelo cerceamento do seu direito de estudar e se formar na "idade certa". É interessante observar que os alunos que evidenciaram sentimentos negativos são aqueles que saíram recentemente do regular.

Ao serem orientados para relatar suas experiências de EJA na escola, observamos que enquanto os concludentes declaram gratidão à essa modalidade porque, segundo eles, ela os tornou mais responsáveis, maduros e melhores, o grupo da alfabetização vai destacar habilidades em que ele se percebe conquistando e descobrindo o mundo das letras e dos números; territórios até então inexplorados. A seguir, declaração do Aluno 7, 32 anos, do 1 o período, quando indagado sobre como se sentia por ser aluno da EJA. Ele afirma:

\footnotetext{
"Aprendi muito bem aqui. Aqui, aprendi ler, escrever palavras e falar palavras... que antes, eu não sabia falar as palavras direito... aprendi também a falar e formar as palavras e aprendi a fazer conta... qualquer conta que me pedir para fazer, eu faço. Antes, não sabia nada não... agora, sei somar, dividir... Aprendi com a professora. De primeiro, não sabia nem as horas nesse relógio, agora sei... antes tinha um relógio digital; agora, esse aqui" (ALUNO 7).
}

Essa declaração aponta para a discussão que Arroyo (2003) tem levantado sobre a importância da escola enquanto elemento transformador da realidade individual e social.

\section{OS PROFESSORES DESSES ALUNOS}

No que diz respeito aos professores, destacamos que todos têm mais de 5 anos de experiência na EJA, alguns estão na Escola desde o primeiro ano de oferta da modalidade, em 1999, e trabalham num outro horário com turmas do regular. São graduados na área em que atuam e possuem pós-graduação em áreas afins. Todos disseram haver vantagens/facilidades com o trabalho, exceto um deles. As justificativas versaram em torno da relação de maturidade, necessidade do estudo no trabalho e o fato de não haver indisciplina, o que facilita o trabalho do professor, fazendo com que as relações pessoais sejam boas. E que a falta de base escolar do aluno faz com que ele seja mais interessado em ouvir o professor.

$\mathrm{Na}$ questão que buscava identificar o(s) desafio(s) no trabalho com a EJA, os professores abordaram a falta de material didático específico para a modalidade, a heterogeneidade das turmas e a falta de um supervisor escolar, que conheça as especificidades da modalidade. Nas questões que pretendiam evidenciar os aspectos da visão do professor com a EJA, percebemos que eles reconhecem que fatores da vida do aluno interferem no desempenho e até mesmo na continuidade dos estudos. Destacamos que na visão de quase a totalidade dos professores os alunos da EJA constituem dois grupos distintos: um grupo de alunos acima de 20 anos e outro, o de alunos abaixo dos 20.

De acordo com suas explicações, essa idade representa "um divisor de águas" entre esses dois grupos. O primeiro caracteriza-se por ter pessoas determinadas, interessadas e com objetivos de vida e de escola bem definidos. O segundo grupo caracteriza-se basicamente pelo mesmo percurso na trajetória escolar: são alunos vindos do ensino regular depois de problemas de indisciplina e sucessivas reprovações.

Interessa observar que todos os professores das turmas concludentes afirmam que os alunos voltam a estudar movidos pelos imperativos do mercado, embora os professores das turmas iniciantes destaquem que para além dessa ordem, seus alunos voltam, movidos pela busca de satisfação pessoal: alguns porque querem ler a Bíblia, outros por vergonha de falar que não sabem assinar o próprio nome, outros para sair de casa, da solidão, para se socializarem e terem outros contatos. Sobre o rendimento dos alunos, todos os professores reconhecem que os alunos avançam num ritmo lento, tendo sempre como referência o regular.

\section{ELES POR ELES}

De modo geral, a análise dos resultados dos alunos aponta que eles vêem a EJA como possibilidade de conclusão dos estudos, ainda que os dois grupos apresentem opiniões bem distintas sobre a modalidade: os iniciantes a percebem como possibilidade de sair da exclusão à qual são submetidos no mundo dos letrados, os concludentes entendem a escolaridade como pré-requisito para a colocação no mercado de trabalho. Acreditam, entretanto que são/serão excluídos do mercado porque a EJA não lhes dá base suficiente para ter uma boa colocação nele, e reconhecem que ela venha contribuindo para melhoria de seu comportamento e amadurecimento. 
Por outro lado, a análise do material dos docentes mostra a visão destes em relação à modalidade e percebemos que em determinados pontos, ela se aproxima e em outros ela se distancia daquilo que os alunos vêm apontando. Para facilitar, apresentaremos quadro com apontamentos de um e de outro, a saber:

\begin{tabular}{|l|l|}
\hline APONTAMENTO DOS ALUNOS & APONTAMENTO DOS PROFESSORES \\
\hline $\begin{array}{l}\text { A escola é promotora de mudanças no } \\
\text { comportamento; }\end{array}$ & $\begin{array}{l}\text { Os fatores da vida do aluno acabam por interferir no } \\
\text { sucesso escolar dele; }\end{array}$ \\
\hline $\begin{array}{l}\text { O concludente busca a inserção no mercado de } \\
\text { trabalho; }\end{array}$ & A heterogeneidade é marca da EJA; \\
\hline O iniciante busca a inserção no mundo das letras; & $\begin{array}{l}\text { Os alunos iniciantes e concludentes constituem } \\
\text { grupos distintos: o aluno com mais de } 20 \text { anos é } \\
\text { o aluno com menos de 20, tem menos interesse, } \\
\text { mas tem mais facilidade; }\end{array}$ \\
\hline $\begin{array}{l}\text { Ser aluno da EJA é motivo de orgulho para } \\
\text { muitos; }\end{array}$ & $\begin{array}{l}\text { A falta de material didático constitui desafio no } \\
\text { trabalho com a EJA; }\end{array}$ \\
\hline $\begin{array}{l}\text { Ser aluno da EJA é motivo de vergonha para } \\
\text { outros porque a sociedade discrimina; }\end{array}$ & $\begin{array}{l}\text { As relações pessoais na EJA são as melhores na } \\
\text { escola; }\end{array}$ \\
\hline $\begin{array}{l}\text { O aluno da EJA não aprende tanto quanto o } \\
\text { aluno do regular. }\end{array}$ & O aluno da EJA rende menos que o aluno do regular; \\
\hline A diferença de idade as turmas é positiva; & $\begin{array}{l}\text { O ensino regular é o parâmetro para todo os } \\
\text { trabalhos; }\end{array}$ \\
\hline $\begin{array}{l}\text { As relações pessoais na EJA são as melhores na } \\
\text { escola; }\end{array}$ & O trabalho compromete o rendimento do aluno; \\
\hline Não existe problema de indisciplina; & Não existe problema de indisciplina; \\
\hline Todos têm objetivos de vida bem definidos; & Os objetivos não são os mesmos; \\
\hline Tempo mais curto é uma vantagem; & O tempo escolar mais curto é um problema; \\
\hline Trabalho e estudo são conciliáveis; & Trabalhar com a EJA é motivo de satisfação; \\
\hline
\end{tabular}

\section{A ANÁLISE DAS INFORMAÇõES E O INSTITUINTE}

Os elementos aqui levantados apontam para reflexões que constituem os desafios da EJA. Embora bastante discutido na literatura, confirma-se que a questão do direito à educação é elemento fundamental para a consolidação de políticas que norteiam a sua prática a fim de assegurar "processos de aprendizagem pelos quais os sujeitos se produzem e se humanizam, ao longo de toda a vida" (PAIVA, 2006, p 522). Entretanto, o reconhecimento desse direito é apenas o início de uma longa caminhada que se fará a partir da concretização desses processos para todos os sujeitos da EJA.

De acordo com Paiva (2006), a compreensão do conceito de direito se reveste, na contemporaneidade, em valor conquistado pelas sociedades, num espaço fértil de disputa, negação e conquista. Essa compreensão se relaciona com o processo democrático assumido pelas sociedades contemporâneas em movimentos de constante tensionamento na conquista da igualdade entre os seres humanos. Para ela, a educação, embora princípio indiscutível e reconhecido como direito humano, no campo da EJA não tem conseguido efetivar-se em políticas públicas que garantam o dever da oferta por parte dos sistemas de ensino. Nas palavras de Paiva: "[...] não é por falta de letra, nem da lei, nem de outros usos da cultura escrita, que o direito não se faz prática”, ele não se efetiva, principalmente porque tais práticas se estabelecem em contextos marcados pela exclusão e pela desigualdade, resultante da conformação ideológica que justifica a concentração do capital (2006, p. 532). Arroyo (2005) destaca que o sistema escolar continua a pensar em sua lógica interna, fechado em si, e nem sempre tendo facilidade nem condição de abarcar a pluralidade das discussões e das novas concepções sobre EJA, realizadas nos espaços de estudo e pesquisa, fora da escola. Para superar tais diferenças, há a necessidade de pensar as suas especificidades no conjunto das políticas públicas e na peculiaridade das políticas educativas.

Para ele, não há dúvida de que o analfabetismo e os baixos índices de escolaridade da população jovem e adulta são indicadores de que o país está longe da garantia universal do direito à educação, pois entende que esse direito transcende à ótica da escola que, até há bem pouco, traduzia-se na suplência da carência escolar. Destaca que a compreensão do direito acena, sem dúvida, para um novo olhar sobre os sujeitos da EJA, no qual a visão distorcida e reducionista com que foram tratados e que os tinha apenas como sujeitos com "trajetórias escolares truncadas e incompletas", deve dar lugar ao protagonismo cultural e social a partir de novos tempos de vida e de direito. Nas suas palavras: "A finalidade não poderá suprir carências de 
escolarização, mas garantir direitos específicos de um tempo de vida. Garantir direitos dos sujeitos que os vivenciam (ARROYO, 2005, p.21)". Esclarece ainda que tal máxima não pretende secundarizar a universalização do direito à educação, mas de não separar esse direito das formas concretas em que ele é negado pois: [...] "Cada jovem e adulto que chegam à eja são náufragos ou vítimas do caráter pouco público de nosso sistema escolar. Um espaço será público quando adaptado às condições de vida em que o povo pode exercer seus direitos" (ARROYO, 2005, p. 48).

Para a configuração de um novo campo específico, considerando os tempos de vida dos sujeitos da EJA, é preciso ter bem definido quem são eles, jovens e adultos, partindo das suas formas concretas de viver seu direito à educação, ao conhecimento, à cultura, à memória, à identidade, à formação e ao desenvolvimento pleno. Esse olhar deverá identificá-los como jovens e adultos em tempos e percursos próprios, aos quais se revelam limites e possibilidades de serem reconhecidos como sujeitos de direito humano (ARROYO, 2005, p. 23).

Ele compreende que os inegáveis avanços do sistema escolar formal põem em discussão a reconfiguração da EJA a partir desses mesmos avanços. Destaca como sendo avanços a ênfase no conhecimento a ser transmitido, o ordenamento dessa transmissão, as didáticas para aprendizagem, a formação dos profissionais, entre outros e, chama à atenção para a tensão existente entre o sistema formal e a modalidade, uma vez que ambos, ao longo da história, percorreram caminhos distintos.

O primeiro, "feito à medida dos filhos desocupados e bem-cuidados", tem dado ênfase ao conhecimento e seus processos de transmissão e controle, enquanto que a EJA foi se concretizando à margem do sistema formal, a partir de campanhas, movimentos sociais e voluntariados, tentando dar conta dos sujeitos reais, portadores de direitos e deles excluídos porque suas trajetórias humanas não se encaixam/encaixaram nas determinações fixas do sistema formal.

Esse autor avalia que a dinâmica do sistema formal não comporta a EJA, até mesmo porque, está na dimensão desta, abarcar os coletivos sociais excluídos daquela. Entretanto, chama a atenção para o fato de, mesmo a Educação de Jovens e Adultos sempre estando à margem do sistema formal, sua análise sempre se faz em comparação a esse mesmo sistema, o que de certa forma, justifica as conclusões que a tomam como distante do ideal de educação.

Nesse sentido, cabe destacar que muitas das "carências" apontadas, a partir dos parâmetros da educação formal, podem ser revertidas em virtudes já que as vantagens daquela terminam por serem estruturadas em lógicas de tempo, espaço e organização do trabalho pedagógico que têm se tornado empecilho às modernas concepções do direito universal à educação.

Se a revisão do sistema educacional se propõe a superar a estrutura seletiva, hierárquica e rígida de organizar o direito ao conhecimento e à cultura, torna-se uma imposição buscar outros parâmetros para a configuração da EJA, desde que a perspectiva do direito seja mantida. Nesse debate, ganha ênfase o fazer pedagógico e os processos de formação do educador da EJA, considerando os seus coletivos tanto como portadores de direitos quanto como possuidores de trajetórias históricas de constante negação.

Sobre a EMEF Professor João Pinto Bandeira, como já afirmado, dispõe de situação favorável no tocante ao quadro de professores, uma vez que a maioria deles compõe a equipe há, pelo menos, cinco anos, diferente de outras escolas que, a cada ano, muda o seu quadro docente. Entretanto, apesar do vínculo institucional, a Escola ainda não conseguiu criar uma sistemática de trabalho que possa aliar teoria e prática.

Nesse sentido, vale destacar um ponto interessante: Paulo Freire é presença forte na tradição da EJA, considerando a sua contribuição no Movimento de Educação Popular. É grande a presença de seus postulados na proposta de educação para o jovem e o adulto. Na perspectiva freiriana, a EJA se traduz no diálogo entre os saberes da tradição popular e escolar. Entretanto, apesar da referência à concepção freiriana, a EJA ainda reproduz e se define a partir dos parâmetros da escola regular, com sua rigidez, hierarquia, disciplina e grades curriculares fechadas: a simples transposição da escola convencional.

Essa presença mais espiritual que material da concepção freiriana na EJA nos permite observar a partir da análise dos dados dos professores que eles têm compreensão das necessidades do seu aluno, no entanto, se vêem em dificuldades, visto que a escola, presa aos padrões do ensino regular não consegue oferecer um ensino que possa contemplar tais necessidades.

As pessoas que tomam o caminho de volta à escola, o fazem motivados por darem (re)significação social às competências, valores, habilidades e conhecimentos acumulados ao longo se suas trajetórias. Nesse sentido, o docente precisa estar preparado para interagir com o estudante, estimulando o exercício do diálogo, de modo a valorizar a experiência que o aluno traz, estabelecendo as possíveis conexões entre o saber vivenciado e o científico. Paiva (2006) afirma que a história de EJA vem se constituindo como uma história de 
experiências $^{4}$ no país uma vez que ela tem acontecido como ação pontual, para atender a uma emergência, realizado predominantemente na esfera da alfabetização, com pouca duração e alta rotatividade dos profissionais.

Segundo a autora, a "volatilidade" dos projetos impede que sejam efetivados vínculos que justifiquem desde o investimento da formação para o trabalho quanto a identidade como as especificidades da modalidade (p. 533). Ela entende que o desafio de efetivar vínculos institucionais significa a possibilidade de construir espaços de formação que vão se forjando a partir do estudo e da prática permanentes.

Assim, discutir a preparação e a formação do educador é profissionalizar, um campo até então tratado como provisório, por se acreditar que os seus sujeitos fossem residuais. Pergunta-se: como residuais, se quase 16 milhões de brasileiros com 15 anos ou de mais idade não têm o domínio da leitura e da escrita? Isso sem contar os quase 60 milhões sem o ensino fundamental completo [...]. Dessa forma, assegurar o direito dos coletivos sociais saírem da condição de excluídos do processo de escolarização passa pela necessidade de programas de formação de educadores para a EJA, tendo como foco o jovem e o adulto, sujeitos de direito e não de favores (ARROYO, 2005).

E entre os desafios postos, está o de colocar a formação do educador de jovens e adultos como garantia das condições de acesso e permanência na escola. Para Arroyo (2005), a EJA é especialmente instigante para a pedagogia e a docência porque favorece o constante repensar das relações sociais e existenciais. As indagações por que passam o professor da EJA fogem das questões do saber instrumental e rumam para as grandes interrogações da condição humana; questões essas que apontam para a dimensão política do ato educativo. E se o docente estiver preparado para essa rica e instigante demanda, novos conteúdos, métodos, tempos, espaços e relações pedagógicas se instalarão.

Compartilhando com Paiva (2006) e Arroyo (2003) na defesa da educação de qualidade para todos os sujeitos, entendemos que a consolidação do PROEJA em São Mateus depende do investimento que deve ir além da Educação de Jovens e Adultos. Entendemos que só expandindo o sentido do PROEJA para a dimensão da educação enquanto direito de todos, é que ele poderá se consolidar enquanto programa capaz de ressignificar a EJA.

Dos dados analisados, percebemos que os professores carregam em sua identidade coletiva a compreensão da escola como uma instituição social para a qual convergem desejos e expectativas variadas, dos mais variados sujeitos, e por isso, recebedora dos mais diferentes sentidos. Todos os sentidos a ela atribuídos reforçam a idéia da escolarização enquanto instrumento de mobilidade social. Os professores, embora reconheçam que a escola seja o espaço autorizado da transmissão/construção do saber e consequente preparação para o mercado de trabalho e para o exercício da cidadania, se sentem despreparados para responderem a tais expectativas. Isso coincide com o que afirma Castoriadis (1995) sobre a instituição da sociedade ser resultante das variadas representações que não se esgotam em uma perspectiva de explicação fundada na determinação de ordem natural, material e histórica, mas que se dá como coexistência de uma quantidade de termos ou de entidades de diferentes ordens e sentidos. Para ele, a prática humana está submetida a determinações do imaginário social o qual consiste numa rede de sentidos que institui histórica e culturalmente o conjunto das interpretações e das experiências vividas no plano individual e materializadas no coletivo (p. 142). Nesse sentido, tudo no mundo social-histórico está entrelaçado por vários elementos que se entrecruzam a partir de um contexto específico, determinado pelo tempo social-histórico, numa espécie de grande rede simbólica.

Assim, convivendo com o instituído (a necessidade da escola para todos) e o instituinte (a clareza de que apenas a oferta dessa escola já não basta), concordamos com Paiva (2006) e Arroyo (2003), quando estes defendem o direito à educação de qualidade para todos.

\section{REFERÊNCIAS}

ARROYO, Miguel Gonzalez. (org.). Da escola carente à escola possível. São Paulo: Edições Loyola, 2003.

Educação de Jovens-Adultos: um campo de direitos e de responsabilidade pública. In: SOARES, Leôncio (org.) Diálogos na educação de jovens e adultos. Belo Horizonte: Autêntica, 2005.

CASTORIADIS, Cornelius. A instituição imaginária da sociedade. (tradução de Guy Reynaud) 3. ed. Rio de Janeiro: Paz e Terra, 1995.

IBGE, Instituto Brasileiro de Geografia e Estatística. Disponível em: http://.ibge.gov.br. Acesso em junho de 2010.

PAIVA, Jane. Tramando concepções e sentidos para redizer o direito à educação de jovens e adultos. In: Revista Brasileira de Educação. Campinas, n. 33, p. 519-538, set/dez. 2006

\footnotetext{
${ }^{4}$ Exceção disso seria o Movimento de Educação de Base - MEB, o Movimento Brasileiro de Alfabetização - MOBRAL, o SESC Ler, os projetos de alfabetização do SESI, do MST e das Secretarias de Educação dos Estados da Bahia e do Rio de Janeiro.
} 